\title{
Luminescence Dating of Middle Pleistocene Glaciofluvial Sediments of the Austrian Northern Alpine Foreland
}

\author{
Lukas Bickel
}

$\begin{array}{ll}\text { E-Mail: } & \text { lukas.bickel@illwerke.at } \\ \text { University: } & \text { Institute of Applied Geology, University of Natural Resources and Life Sciences, Vienna, Austria } \\ \text { Supervisors: } & \text { Markus Fiebig, Christopher Lüthgens, Johanna Lomax } \\ \text { Present affiliation: } & \text { Vorarlberger Illwerke AG, Vandans, Austria }\end{array}$

Dissertation:

http://permalink.obvsg.at/bok/AC10778641 (not provided online)

In the beginning of the 20th century, Albrecht Penck und Eduard Brückner (1909) developed the concept of four large scale Quaternary alpine glaciations extending into the alpine foreland. Since then, the Northern Alpine Foreland (NAF) has played a major role in the investigation of glacial and furthermore paleo-climatic events. However, a numerical chronology has not been established yet. This study focuses on applying luminescence dating to the glaciofluvial deposits attributed to the penultimate glaciation (Riß glaciation, correlated to marine isotope stage 6) when vast areas of the inner Alps were completely glaciated (Figure 1). In the easternmost part of the Alps, the glaciers did not reach the foreland, but formed valley glaciers confined by the mountainous terrain.

Samples for luminescence dating purposes were taken from glaciofluvial sediments mainly deposited in the form of river terraces in the alpine foreland. Samples were collected from 6 river basins for analysis within this $\mathrm{PhD}$ thesis (rivers from East to West: Ybbs, Enns, Steyr, Krems,Traun, and Salzach).

On the one hand, this study explored the luminescence properties of quartz and feldspar regarding their potential as robust dosimeters for dating glaciofluvial sediments of the penultimate glaciation in the Austrian NAF (BICKEL et al. 2015a, BICKEL 2016). On the other hand, the main goal was the construction of a reliable and robust chronology of the deposits.

A highly dynamic depositional environment, such as a glacier-fed river system, implies the possibility of incomplete resetting of the luminescence signal - in particular when transport distances are short. In an environment like this, quartz is the mineral of choice over feldspar, especially if dose rates are low and theoretically allow gaining quartz ages beyond $150 \mathrm{ka}$.
However, detailed analyses of the quartz OSL signal characteristics had revealed the presence of a thermally unstable medium component in some samples. Because of the lack of independent age control in the expected age range, it remained unclear whether this medium component may result in significant age underestimation for the affected samples (BICKEL 2016). Therefore, the luminescence properties of coarse grain potassium-rich feldspar $(100-200 \mu \mathrm{m})$ were analyzed as well and revealed a general suitability for luminescence dating purposes. To obtain a robust dataset and reliable age estimates for the samples, three luminescence signals were investigated for each sample: blue stimulated quartz OSL, infrared stimulated feldspar luminescence at $50^{\circ} \mathrm{C}$ (IRSL) and at an elevated temperature of $225^{\circ} \mathrm{C}$ (pIRIR). By comparing the results gained from all three analytical approaches, it was possible to discern between samples that were well bleached prior to deposition and samples for which the luminescence signals were not properly reset (BICKEL 2015a,b).

Using this comparative dating approach, it was possible to establish a reliable chronology for the glaciofluvial deposits attributed to the penultimate glaciation in the NAF. For the first time, it was possible to establish a methodologically and stratigraphically coherent age determination of the formation of terrace sediments during the penultimate glaciation in the Austrian NAF. Additionally, in comparison with previous studies from other alpine regions it was possible to show, that the transition between glacial and interglacial conditions happened relatively fast in late MIS6/starting MIS5 (BICKEL et al. 2015b). Even though the dating results allow to discern between glacial and interglacial periods, a finer resolution on a stadial/interstadial level cannot be obtained solely using the current state-of-the art methods of luminescence dating as applied in this study. 


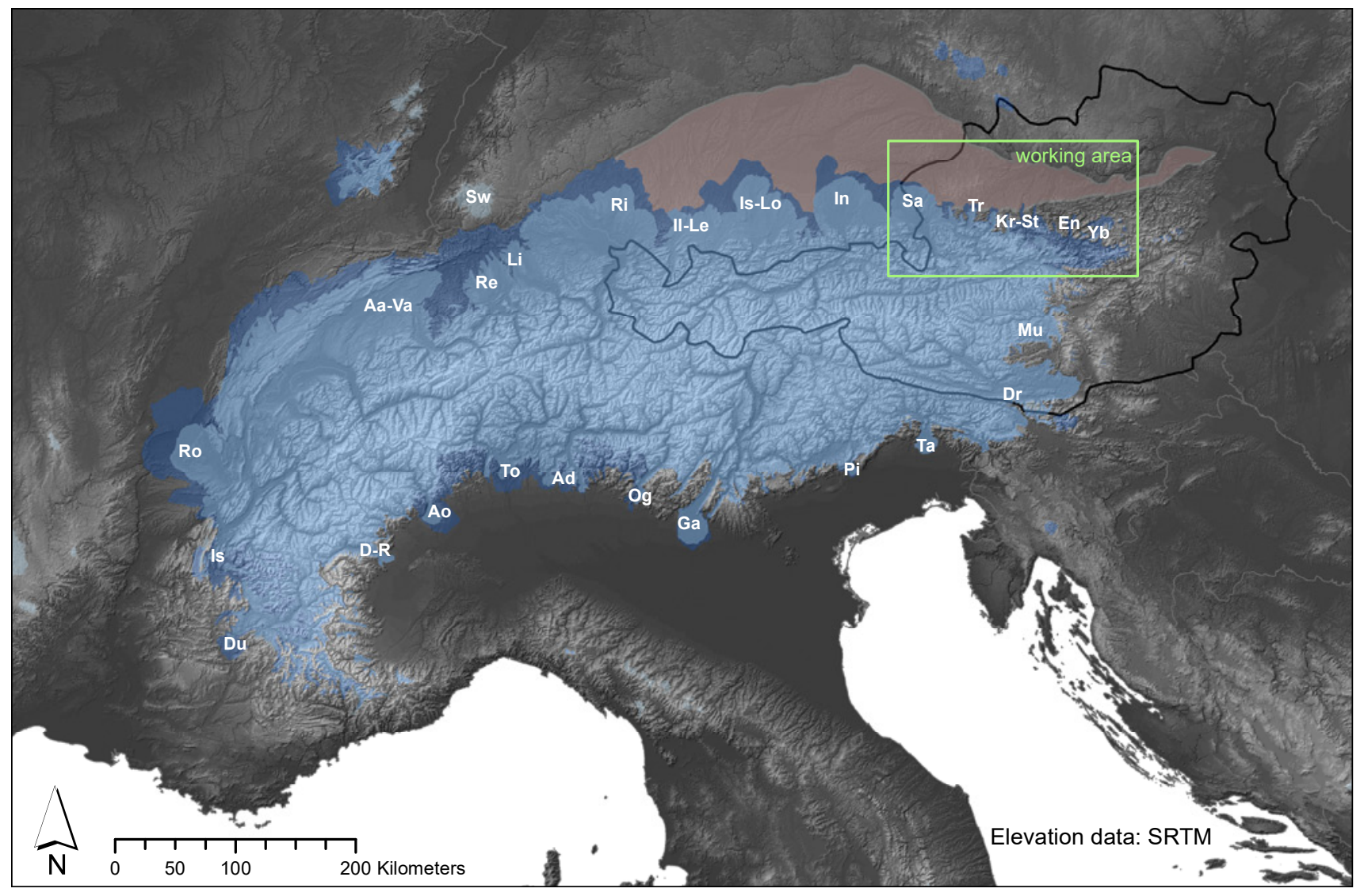

Fig. 1: Ice extent of the last (light blue) and penultimate (dark blue) glaciations of the Alps and surrounding areas. (modified after EHLERS \& GIBBARD 2004, КонL 2000). The Northern Alpine Foreland is indicated with a reddish overlay. The working area is framed by a green rectangle. Main glacier systems: Aa-Va...Aare-Valais, Ad...Adda, Ao...Aosta, D-R...Dora Riparia, Dr...Drau, Du...Durance, En...Enns, Ga...Garda, Il-Le...Iller-Lech, In...Inn, Is...Isère, Is-Lo... Isar-Loisach, Kr-St...Teichl-Steyr-Krems, Li...Limmath, Mu...Mur, Og...Oglio, Pi...Piave, Re...Reuss, Ri...Rhine, Ro...Rhône, Sa...Salzach, Sw...Schwarzwald, Ta...Tagliamento, To...Toce, Tr...Traun, Yb...Ybbs.

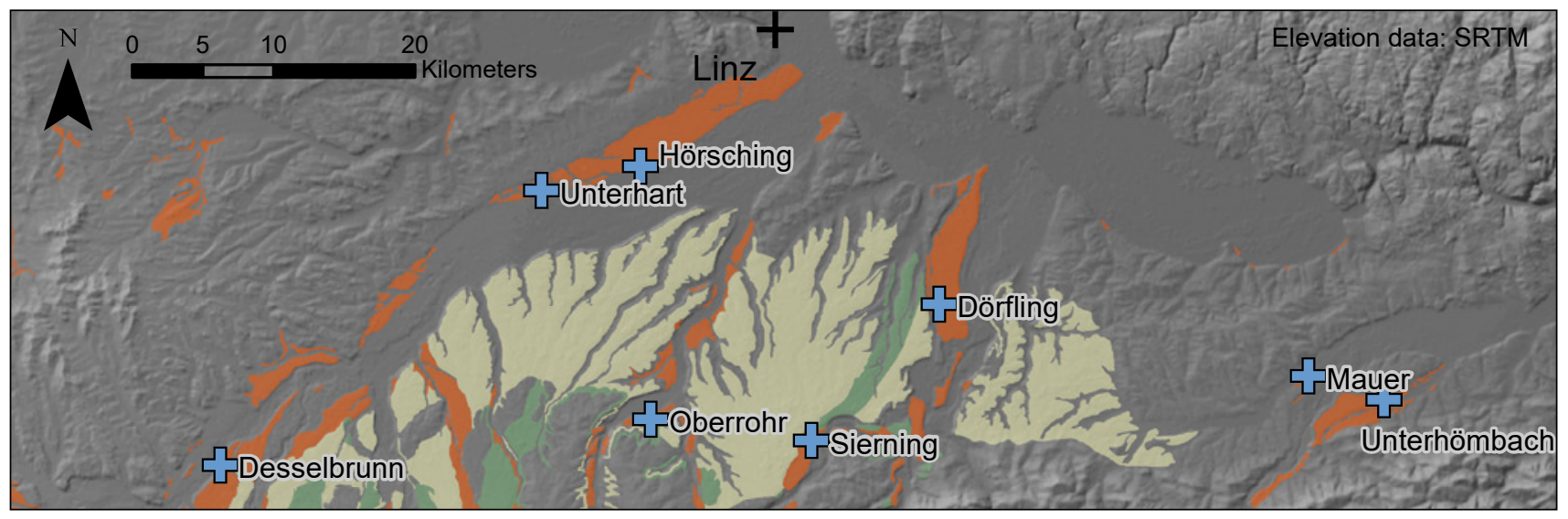

Fig. 2: Overview of the main working area - the „Traun-Enns-Platte“(Traun-Enns-Plateau). Red: High Terrace, green: Younger Cover Gravel, yellow: Older Cover Gravel. Blue crosses represent sampling locations.

\section{References}

BICKEL, L. (2016): Luminescence dating of Middle Pleistocene glaciofluvial sediments of the Austrian Northern Alpine Foreland. - Phd thesis, BOKU - University of Natural Resources and Life Sciences, Vienna, 166 p., Vienna. http://permalink.obvsg.at/bok/AC10778641

Bickel, L., LÜthgens, C., Lomax, J., \& FieBIG, M. (2015a): Luminescence dating of glaciofluvial deposits linked to the penultimate glaciation in the Eastern Alps. - Quaternary International, 357, 110-124. http://doi. org/10.1016/j.quaint.2014.10.013
Bickel, L., LÜthgens, C., Lomax, J., Ð Fiebig, M. (2015b): The timing of the penultimate glaciation in the northern Alpine Foreland: New insights from luminescence dating. - Proceedings of the Geologists' Association, 126(4-5). http://doi.org/10.1016/j.pgeola.2015.08.002

Ehlers, J. \& GibBard, P. (Eds.) (2004): Quaternary Glaciations-extent and Chronology: Part I: Europe, supplementary data. - Elsevier.

KoHL, H. (2000): Das Eiszeitalter in Oberösterreich. - Schriftenreihe ed. Oberösterreichischer Musealverein, 487 p., Linz.

Penck, A. \& Brückner, E. (1909): Die Alpen im Eiszeitalter. - Bd. 1. Die Eiszeiten in den nördlichen Ostalpen. p. 393. 